Running head: Sports and Disturbed Eating Attitudes

\title{
Prevalence and Sport-Related Predictors of Disturbed Eating Attitudes and Behaviors: Moderating Effects of Sex and Age
}

Marie-Christine Lanfranchi $^{\mathrm{a}, \mathrm{b}}$, Christophe Maïano ${ }^{\mathrm{c}}$, Alexandre J. S. Morin ${ }^{\mathrm{d}}$, Pierre Therme ${ }^{\mathrm{a}}$

a Aix-Marseille Univ \& CNRS, UMR 7287 “ Institute of Movement Sciences, Etienne-Jules Marey”, Marseille, France.

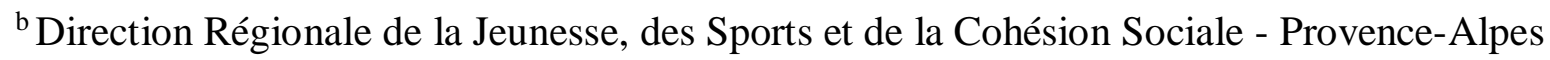
Côte-d’Azur, Marseille, France.

${ }^{\mathrm{c}}$ Cyberpsychology Laboratory, Department of Psychoeducation and Psychology, Université du Québec en Outaouais (UQO), Canada.

${ }^{\mathrm{d}}$ Centre for Positive Psychology and Education, University of Western Sydney, Australia.

Correspondence concerning this article should be addressed to: Christophe Maïano,

Université du Québec en Outaouais, Campus de Saint-Jérôme, Département de

Psychoéducation et de Psychologie, 5 rue St-Joseph, Saint-Jérôme (Québec), J7Z 0B7, email: christophe.maiano@uqo.ca

This is the final prepublication version of:

Lanfranchi, M.-C., Maïano, C., Morin, A.J.S., \& Therme, P. (2014). Prevalence and Sport-Related Predictors of Disturbed Eating Attitudes and Behaviors: Moderating Effects of Sex and Age. Scandinavian Journal of Medicine and Science in Sports, 41 (5), 775-788. 


\begin{abstract}
Very few studies examined the prevalence and sport-related predictors of disturbed eating attitudes and behaviors (DEAB) among adolescents involved in sport practice, and their results are mixed and inconclusive. These inconsistencies are most likely due to their methodological heterogeneity, and to the fact that none of these studies took into consideration the potentially relevant characteristics of the sport practice context. This study attempts to answer this limitation among French adolescents not-involved or involved in various sports contexts defined based on their organization, leanness-centration, and competitive level. Participants were 335 adolescents involved in sport practice, and 435 adolescents not-involved in any form of regular sport practice. The DEAB were measured using the Eating-Attitudes Test-26. Global results do not showed any significant association between the status of the participants and DEAB. However, these results drastically changed when we considered the potential moderating role of sex and age on these relations. Indeed, sports involvement in general, and involvement in leanness and competitive sports were found to exert sex and age differentiated effects on the risks of presenting clinically significant levels of DEAB. This study suggests the importance of monitoring, preventive and early intervention mechanisms within the context of practice, particularly for adolescent girls.
\end{abstract}

Key words. Fear of getting fat, social pressure to gain weight, vomiting-purging behavior, eatingrelated control and guilt, food preoccupation, sport modality and context, competition level, leanness. 


\section{Prevalence and Sport-Related Predictors of Disturbed Eating Attitudes and Behaviors: Moderating Effects of Sex and Age}

The prevalence and sport-related determinants of disturbed eating attitudes and behaviors (DEAB) among youths involved in sport practice have been increasingly studied in the past two decades (Beals, 2004; Dosil, 2008; Thompson \& Sherman, 2010). In these studies, DEAB are abnormal eating-related attitudes (e.g., fear of getting fat, drive for thinness, etc.) and behaviors (e.g., restrictive eating, fating, overeating, using diet pills, laxatives or diuretics, etc.). This term is "generally accepted as a non-clinical concept and originate from self-reported scales” (Coelho et al., 2010, p. 380), which is distinct from eating disorders that refers to a more specific subgroup of individuals with clinical diagnoses of anorexia or bulimia nervosa (Krentz \& Warschburger, 2011).

Based on recent reviews (Baum, 2006; Beals \& Manore, 1994; Byrne \& McLean, 2001; Glazer, 2008; Sundgot-Borgen, 1994; Thompson \& Sherman, 1999) and meta-analyses (Coelho, Soares, \& Ribeiro, 2010; Hausenblas \& Carron, 1999; Smolak, Murnen, \& Ruble, 2000; Thein-Nissenbaum \& Carr, 2011) it is currently recognized that: (a) youths involved in sport practice exhibit elevated prevalence rates of DEAB; (b) female involved in sport practice present a greater risk of DEAB than male involved in sport practice; (c) adolescents competing in leanness sports, such as those emphasizing lean body shapes (e.g., figure skating, gymnastics, synchronized swim, etc.) or controlled body weight (e.g., judo, taekwondo, rowing, etc...) present a higher risk of DEAB than those competing in other types of sports; and (d) adolescents competing in elite sports were more vulnerable to DEAB than those competing in non-elite sports.

During the past decade scholars (e.g., Nichols, Rauh, Barrack, Barkai, \& Pernick, 2007; Nichols, Rauh, Lawson, Ji, \& Barkai, 2006; Rauh, Nichols, \& Barrack, 2010; Thein-Nissenbaum, Rauh, Carr, Loud, \& McGuine, 2011) examined the prevalence rates and sport-related determinants of DEAB (as well as menstrual irregularity and low bone mineral density) among youths involved in sport practice. However, as noted in recent reviews and meta-analyses (e.g., Baum, 2006; Coelho et al., 2010; Glazer, 2008; Tamminen, Holt, \& Crocker, 2012; Thein-Nissenbaum \& Carr, 2011), few of these studies were controlled and these yielded mixed and inconsistent results. This is especially surprising since DEAB are known to frequently emerge during adolescence, following pubertal development (Hoek, 2006; 
Hoek \& van Hoeken, 2003), a period where youths are known to be particularly sensitive to the influence of extra-familial contexts (Dosil, 2008; Thompson \& Sherman, 2010), such as the sport context for youths involved in sport practice.

For instance, in research conducted among adolescent girls, several studies revealed higher prevalence rates of DEAB in adolescents involved in sport practice than in other adolescents (e.g., Anshel, 2004; Ferrand, Champely, \& Filaire, 2009; Filaire, Rouveix, Bouget, \& Pannafieux, 2007; Neumärker, Bettle, Bettle, Dudeck, \& Neumärker, 1998; Rouveix, Bouget, Pannafieux, Champely, \& Filaire, 2007; Van Durme, Goossens, \& Braet, 2012), whereas other studies rather reported opposite results (e.g., Martinsen et al., 2010; Rosendahl et al., 2009) or non-significant differences (e.g., Abraham, 1996; Hoch et al., 2009; Monthuy-Blanc et al., 2010; Ravaldi et al., 2003; Toro et al., 2005; Toro, Guerrero, Santis, Castro, \& Puértolas, 2009). In addition, only a handful of studies (e.g., Ferrand et al., 2009; Martinsen et al., 2010; Monthuy-Blanc et al., 2010; Ravaldi et al., 2003; Rosendahl et al., 2009; Rouveix et al., 2007) examined the associations between adolescents’ DEAB and sport-related determinants [i.e., type of sports (e.g., judo vs. ballet dance) or sport groups (e.g., ball game vs. endurance sports); categories of sports (e.g., leanness vs. non-leanness); level of competition (e.g., non-elite vs. elite)], and these studies provided mixed, inconsistent and inconclusive results showing that some elements of sport contexts do seem to have an influence on DEAB-levels, but that these elements differ across studies in a non-systematic manner. These results can likely be explained by the incomplete and highly inconsistent array of sport context characteristics considered in these studies, making it hard to contrast their results in a systematic manner and pointing to the need for comprehensive epidemiological studies in which broader array of sports’ context characteristics are taken into account.

In contrast to adolescent girls, there have been even fewer studies conducted among adolescent boys involved in sports practice (e.g., Filaire et al., 2007; Neumärker et al., 1998; Martinsen et al., 2010; Ravaldi et al., 2003; Rouveix et al., 2007; Rosendahl et al., 2009; Van Durme et al., 2012), and these studies also provided highly inconclusive results. For instance, some report non-significant differences in rates of DEAB between boys involved in sport practices and other adolescents (Filaire et al., 2007; Neumärker et al., 1998; Rosendahl et al., 2009; Rouveix et al., 2007; Van Durme et al., 
2012). Other rather report significantly higher prevalence rates in boys not-involved in sport practice (Martinsen et al., 2010) or significantly higher prevalence rates boys involved in sport practice (Ravaldi et al., 2003). Moreover, only two studies examined the potential association between DEAB and sport-related characteristics (Martinsen et al., 2010; Rosendahl et al., 2009) and showed: (a) a lower risk of DEAB among boys involved in ball game sports, and a higher risk of DEAB among boys involved in antigravitation sports such as climbing, where weight control is an important issue (Rosendahl et al., 2009); (b) either higher rates of DEAB in leanness sports (Rosendahl et al., 2009) or a lack of significant differences between leanness and non-leanness sports (Martinsen et al., 2010); and (c) a lack of significant differences between boys not involved in sport practice and boys competing in non-elite or elite sports (Rosendahl et al., 2009).

As previously noted, these inconsistencies in results regarding the associations between DEAB and the sport context among adolescents boys and girls is most likely due to the high level of methodological heterogeneity of these studies. Indeed, these studies relied on: (a) different criterions to define DEAB (e.g., clinical rates, non-clinical rates, continuous levels) based on non-national and sex-matched cut-off scores or percentile ranks to define DEAB levels; (b) a single (global) DEAB score, or a multidimensional conception of DEAB based on multiple criterions, or symptoms; (c) different self-reported instruments to measure DEAB based on diagnostic criterions, attitudes, behavioral manifestations, or combinations; (d) a limited age range solely comprising either early (1114 years) or late (15-18 years) adolescents; (e) unmatched control groups; (f) a single type of sport or a very limited range of sports, mostly emphasizing leanness or weight restrictions (e.g., ballet, cycling, figure skating, gymnastics, swimming, judo); (g) inconsistent classifications of the types of sports considered (leanness vs. non-leanness, etc.); and (h) adolescents competing at a non-elite, elite or unspecified level of sport practice.

Moreover, these studies also present multiple limitations. First, most relied on a small sample sizes of adolescents involved in regular sport practice $(<100)$ of dubious generalizability, making it difficult to trust prevalence estimates of DEAB (Martinsen et al., 2010; Rosendahl et al., 2009). Second, most of the sport-related characteristics commonly studied or associated with DEAB in adults [sport groups (i.e., aesthetic, ball game, antigravitation, etc.), sport classifications (i.e., leanness vs. 
non-leanness), competition level (i.e., non-competitive vs. competitive)] were only partially studied, but most often completely ignored, among adolescent involved in sport practice. Third, none of the previous studies conducted among adolescents examined the prevalence rates of DEAB among (a) youths practicing their sport independently (free practice alone or with friends outside the school or the club sport context) versus in a more formal context (i.e., school, sports club; for a recent study investigating these characteristics among adults, see Holm-Denoma, Scaringi, Gordon, van Orden, \& Joiner, 2009); and (b) youths exercising in non-competitive sports (for a previous non-epidemiological study investigating this characteristic among adolescents, see Madison \& Ruma, 2003). This is surprising given that a large proportion of adolescent boys and girls are known to practice sport in unstructured and non-competitive contexts (Mota \& Esculcas, 2002; Santos, Gomez, \& Mota, 2005). Fourth, most of the previous studies examined prevalence rates of DEAB and their association with sport-related characteristics among separate sample of boys or girls, and the few studies including mixed-gender samples (e.g., Filaire et al., 2007; Martinsen et al., 2010; Neümarker et al., 1998; Ravaldi et al., 2003; Rouveix et al., 2007; Rosendahl et al., 2009; Van Durme et al., 2012) still conducted their analyses separately without formally verifying whether the estimated relations were significantly moderated by gender (i.e., whether the relations significantly differed according to gender). Similarly, possible developmental differences, illustrated by a significant moderating effect of age, were completely ignored in the context of previous studies, possibly because most of them relied on age-range limited samples. Since DEAB is known to often emerge during adolescence (ChamayWeber, Narring, \& Michaud, 2005; Hoek, 2006; Hoek \& van Hoeken, 2003; Smink, van Hoeken, \& Hoek, 2012), with peak prevalence rates occurring close to 15 years old (Hoek \& van Hoeken, 2003; Smink et al., 2012), this neglect of possible developmental effects is surprising.

The aim of the present study is to answer some of these limitations using a large sample of sexand age-matched French non-involved in sport practice and adolescents practicing sport in various contexts. More precisely, this study aims to verify whether (a) adolescent involved in sport practice present significantly higher rates of DEAB compared with sex- and age-matched youths not-involved in sport practice; (b) sport practice context (unstructured vs. organized sport) may be significantly associated with rates of DEAB among adolescents; (c) adolescents practicing sports at a competitive 
level may present higher rates of DEAB compared with adolescent practicing sports at a noncompetitive level; (d) sport classification (i.e., leanness vs. non-leanness) commonly associated with DEAB rates among adults also present significant associations with rates of DEAB during adolescence; and (e) whether sex and age moderate the associations between rates of DEAB and sports' characteristics.

\section{Method}

\section{Procedure and Participants}

The study was performed following the recommendations of the research ethics committee of the University of Nice, the Nice Academy (local education authority) and the inspector of schools. This study was performed during one academic school year, between September 2007 and June 2008 in schools located in the French Riviera. A total of 10 middle and 10 high schools were contacted and 65\% of these schools (6 middle and 7 high schools) agreed to participate. The reason for schools refusal was a lack of availability at the moment of the study, often due to being involved in other studies at the moment. Participating schools then sent an information letter explaining the purpose of the study to the parent or legal representative of the adolescents. Only the participants who agreed to participate, and who returned signed parental informed consent forms, were included in the study.

A total of 1300 adolescents were contacted and 809 (62.2\% response rate) agreed to participate. However, 39 of these adolescents were excluded from this study because (a) they were either younger than 11 years old or older than 18 years old $(n=26)$; and (b) returned questionnaires in which measures of sport-related characteristics or DEAB were not completed, or impossible to properly score $(n=13)$. The final sample thus comprise 770 adolescents, aged between 11 and 18 years $\left(M_{a g e}=14.61, S D_{a g e}=2.12\right)$, and including: (a) 341 boys (44.3\%) and 429 girls (55.7\%); (b) 527 (68.4\%) participants from European origin, 199 (25.9\%) from African origin, and 44 (5.7\%) from other descents; and (c) 81 (10.5\%) participants classified as underweight, 603 (78.3\%) as having a normal weight, and 86 (11.2\%) as overweight-obese.

The overall sample was divided in two groups of based on their status as being involved $(n=$ 335; 43.5\%; coded 1), or not ( $n=435$; 56.5\%; coded 0$)$, in regular sport practice. Details on the 
anthropometric, demographic, ethnicity and weight categories characteristics of these groups are reported in Table 1. The first group includes adolescents that, in addition to mandatory physical education classes, had been involved in an additional regular sport practice, between one to eight times per week $(M=2.36, S D=1.21)$, between 25 minutes to 12 hours per week $(M=3.33, S D=1.94)$, and for at least one-year for 69\% ( $>$ three-year for $44.9 \%$ ). The second group includes adolescents that were involved in physical education classes as is mandatory in the French education system, but were not currently practicing a sport outside of this physical education context.

The adolescents were involved in the practice of 46 different sports (see a fuller description in the online supplementary materials). For some of the analyses, specific characteristics of these sports and their context of practice were also considered: (a) whether the adolescents exercised in an organized context ( $n=249$; dummy-coded 1 ) or not (all remaining students dummy-coded 0 ); (b) whether the adolescents were involved in competitive sports ( $n=149$; dummy-coded 1$)$ or not (dummy-coded 0); and (c) whether the adolescents were practicing a leanness sport ( $n=134$; dummycoded 1 ) or not (dummy-coded 0 ).

\section{Measures}

Demographic and sport-related characteristics. Participants were asked to self-report: (a) their age, sex, height, weight, and their ethnic origin (i.e., European, African and others); (b) whether they were or not practicing a sport (the most important in time and frequency): independently (i.e., exercising outside the school or the club context), in their school (i.e., outside the physical education curriculum) and/or in a club sport outside the school; and (c) whether they were or not competing in this(these) sport(s) and at which level (i.e., non-elite and/or elite).

Weight categories. They were determined on the basis of the self-reported ${ }^{1}$ height and weight that were then converted to body mass indexes $(\mathrm{BMI})=$ weight/height*height (Cole, 1979). The BMI scores were then used to classified the participants as underweight, normal weight or overweightobese, based on the international cut-off points adjusted for sex and age provided by Cole and Colleagues (Cole, Bellizzi, Flegal, \&Dietz, 2000; Cole, Flegal, Nicholls, \& Jackson, 2007).

Disturbed Eating Attitudes and Behaviors. To ensure comparability with other studies conducted among adolescents samples (e.g., Coelho et al., 2010; Monthuy-Blanc et al., 2010; Thein- 
Nissenbaum \& Carr, 2011), DEAB will be measured with the short version of the Eating Attitudes Test (EAT-26; Garner et al., 1982). The adapted French version of the EAT-26 used in the present study includes 18 items (EAT-18) assessing six dimensions of DEAB: (1) Fear of Getting Fat (FGF; e.g., I am preoccupied with a desire to be thinner, etc.), (2) Social Pressure to Gain Weight (SPGW; e.g., I feel that others would prefer if I ate more), (3) Vomiting-Purging Behavior (VPB; e.g., I vomit after I have eaten), (4) Eating-Related Control (ERC; e.g., I aware of the calorie content of foods I eat), (5) Food Preoccupation (FP; e.g., I feel that food controls my life), and (6) Eating-Related Guilt (ERG; e.g., I feel extremely guilty after eating). The items are rated on a six-point Likert-type scale ranging from always (6) to never (1). This French adapted version was validated by Maïano, Morin, Lanfranchi and Therme (2012) among a large sample ( $n=2178)$ of community adolescents in a series of four studies, which confirmed the adequacy of the psychometric properties (e.g., $\alpha=.69$ to .84 across scales and studies, factor validity, measurement invariance across sample, sex, age, ethnicity and weight categories, and convergent validity with measures of global self-esteem, physical appearance, social physique anxiety and fear of negative appearance evaluation) of this instrument relying on exploratory structural equation modeling (ESEM) and confirmatory factor analyses (CFA). In the present study, the Cronbach alpha coefficients of these scales were all into the acceptable range (FGF: .83, SPGW: .77; ERC: .70; VPB: .69; FP: .68, ERG: .75).

Defining clinical levels of DEAB. The criterions for classifying participants as presenting a clinical level of DEAB were as follows: (a) having a BMI $\leq$ at $17 \mathrm{~kg} / \mathrm{m}^{2}$ (i.e., thinness grade 2) according to the international cut-off points adjusted for sex and age provided by Cole et al. (2007); (b) presenting a score $\geq 19$ and 16 on the FGF scale for girls and boys, respectively; (c) presenting a score $\geq 9$ and 8 on the SPGW scale for girls and boys, respectively; (d) presenting a score $\geq 3$ on the VPB scale for girls and boys, respectively; (e) presenting a score $\geq 16$ and 15 on the ERC scale for girls and boys, respectively; (f) presenting a score $\geq 6$ on the FP scale for girls and boys; and (g) presenting a score $\geq 6$ and 5 on the ERG scale for girls and boys, respectively. These criterions were chosen based on the $85^{\text {th }}$ percentile 2 scores for boys and girls provided by Maïano et al. (2012), and on criterions commonly found in the literature (see Coelho et al., 2010; Thein-Nissenbaum \& Carr, 2011). 
The following characteristics were compared according the sport-practice status of the participants (i.e., involved or not-involved) and their sex: demographic/anthropometric characteristics (i.e., age, height, weight, and BMI), ethnicity (i.e., European, African and others), and weight categories (i.e., underweight, normal weight and overweight-obese). To test for the significance of group-differences, we relied on Kolmogorov-Smirnov $Z$ tests (demographic/anthropometric characteristics) and a $\chi^{2}$ tests ethnicity and weight categories).

Stepwise multivariate logistic regression analyses were used to test the association between rates of clinical levels of DEAB symptoms and sex, age, the sport-practice status of the participants (i.e., involved or not-involved), sport-related characteristics (i.e., organized sport practice context, leanness sports classification, and competition status), and interactions of age and sex with the other predictors (i.e., status of the participants and sport-related characteristics). These analyses were performed in four steps in the prediction of DEAB symptoms: (a) the demographic variables (age and sex) were entered first; (b) the sport-practice status of the participants (i.e., involved or not-involved) was entered in second; (c) the sport-related characteristics were entered in third; and (d) the moderating effects of sex and age in the association between the status of the participants or the sportrelated characteristics and DEAB symptoms were entered last. The associations derived from the analyses were expressed as adjusted odds ratios (OR), with 95\% confidence intervals (95\% CI). In these analyses the age of the participants was centered at the mean in order to reduce potential problems due to non-essential multicollinearity when testing the interaction effects. The statistical level of significance was fixed at $p<.05$.

\section{Results}

\section{Participants Characteristics}

The characteristics of the participants according to their sport-practice status (i.e., involved or not-involved) and sex are described in Table 1. Results from the Kolmogorov-Smirnov $Z$ tests did not show significant differences between adolescents involved or not in sport practice in regards to the demographic/anthropometric, ethnicity, and weight categories variables (see Table 1). Conversely, adolescents involved or not in sport practice differed from one another, showing that the likelihood of being in the normal weight category was significantly higher in those not involved in sport practice 
than for those involved in regular sport practice. The results also show significant sex differences in weight, height, ethnicity and weight categories, so that: (a) boys have a on average significantly higher weight and height than girls; (b) boys were significantly more often classified as having parents from European origin $\left[\chi^{2}(1)=3.88, p=.04\right]$, whereas girls were significantly more often classified as having parents from other origin $\left[\chi^{2}(1)=8.79, p=.003\right]$; and (c) girls were significantly more often classified as being underweight $\left[\chi^{2}(1)=5.45, p=.02\right]$, and boys were significantly more often classified as being overweight-obese $\left[\chi^{2}(1)=8.85, p=.003\right]$. Finally, there was no significant difference between boys and girls in age and BMI (see Table 1).

\section{Association between Disordered Eating, Demographic and Sport-Related Characteristics}

The adjusted ORs for risk of DEAB according to the demographic characteristics of the participants, their sport-practice status and sport-related characteristics are provided in Table 2. First, the results revealed significant associations between sex and Fear of Getting Fat $(p<.05)$ and EatingRelated Guilt $(p<.05)$, showing that boys were 1.5 and 1.6 times less likely to present clinically significant levels of Fear of Getting Fat (in steps 1-3) and Eating-Related Guilt (in steps 1-3) when compare to girls. However, no significant association was found between sex and the other DEAB symptoms $(p>.05)$. Interestingly, these results were not affected by the addition of other predictors (steps 1-3), but faded out when the interactions were included in the model, mostly due to the slight decrease in power associated with an increased number of predictors given that the ORs remained quite similar. Similarly, age presented a significant association with Social Pressure to Gain Weight (steps 1-4), Vomiting-Purging Behavior (steps 1-3) and Eating-Related Control (steps 1-4), showing that an increase of one-year in age was associated with a reduction of 1.1-1.2 times in the risk of presenting clinically significant levels of Social Pressure to Gain Weight, Vomiting-Purging Behavior and Eating-Related Control. Nevertheless, no significant association was found between age and the other DEAB symptoms $(p>.05)$.

Second, adolescents status as being involved in sport on a regular basis presented no significant associations with the various DEAB symptoms considered $(p>.05)$. For instance, the proportions of adolescents presenting clinically significant levels on the symptoms ranged from $2.1 \%$ (Underweight) to 23.3\% (Eating-Related Control) for those involved in sport practice and from 3.7\% 
(Underweight) to 23.2\% (Social Pressure to Gain Weight) for the others (these category-specific prevalence rates are reported in the online appendix). This result thus shows that sport practice per se does not seem related to DEAB. Similarly, when the specific characteristics of the sport context are taken into in the analyses, the results show no significant relations, and three marginally significant ones $(p<.10)$, suggesting that being involved in a leanness sport almost doubled (ORs $=1.81$ and 1.74 respectively) the odds of presenting clinically significant levels of Fear of Getting Fat and EatingRelated Guilt, but that being involved in a competitive sport practice decreased by 1.7 times the risk of presenting clinically significant levels of Eating-Related Control. When the interaction effects are added to the regression, most of these effects becomes non-significant (attesting to significant interactions effects), but of a similar magnitude. However, when the interactions were taken into account in the models for greater precision, the results also revealed that, (a) adolescents involved in sport practice presented marginally significant $(p<.10)$, but notably increased odds (i.e., over twotimes more likely) of presenting clinically significant levels of Social Pressure to Gain Weight (OR= 2.37) and Eating-Related Control $(O R=2.12)$; (b) adolescents involved in competitive sports were approximately 2.5 times more likely to present clinically significant levels of Fear of Getting Fat (OR $=2.21 ; p<.10)$ and Vomiting-Purging Behavior $(O R=2.56, p<.05)$; (b) adolescents involved in leanness sports still had a marginally significant higher odds $(O R=1.68 ; p<.10)$ of presenting clinically significant levels of Eating-Related Guilt.

\section{Moderating Effects of Sex and Age}

The adjusted ORs for risk of DEAB according to the interaction between demographic and sport-related characteristics are provided in the bottom of Table 2.

Sex. A significant interaction effect was observed between sex and the status of the participants in the prediction of Food Preoccupation $(p<.05)$. The decomposition of this interaction revealed that boys involved in sport practice were 3.8 times less likely to present clinically significant levels of Food Preoccupation $(O R=.26$; 95\% CI: .07-.91; $p<.05)$ compared with boys not-involved in sport practice. However, no effect of status was observed among girls (OR $=1.81$; 95\% CI: .774.23; $p=.17$ ), with girls involved or not in sport practice presenting similar levels of Food Preoccupation. Additional analyses revealed that boys involved in sport practice were 5.9 times less 
likely to present clinically significant levels of Food Preoccupation $(O R=.17$; 95\% CI: .04-.72; $p<$ .05) compared with girls involved in sport practice. Nevertheless, no significant differences were observed between boys and girls not-involved in sport practice $(O R=1.18$; 95\% CI: .75-1.86; $p=$ .47), thus suggesting that the main difference was related to an association between sport involvement and a decreased risk of presenting a clinical level of Food Preoccupation among boys.

The results also showed additional marginally significant interactions effects $(p<.10)$. First, a marginally significant association was found between sex and leanness sports in the prediction of Fear of Getting Fat. The decomposition of this interaction revealed that boys involved in leanness sports were 4 times more likely to present clinically significant levels of Fear of Getting Fat (OR=4.04; 95\% CI: 1.37-11.86; $p$ <.05) compared with boys not involved in leanness sports. However, no effects of being involved in leanness sports was observed among girls ( $O R=1.27 ; 95 \% \mathrm{CI}$ : .57-2.82; $p=.57)$. Finally, no significant differences were observed between boys and girls not involved ( $O R=.79 ; 95 \%$ CI: .46-1.36; $p=.40)$ or involved $(O R=2.52$; 95\% CI: .59-10.75; $\mathrm{p}=.21)$ in leanness sports. This suggests that the main difference was related to an association between involvement in leanness sports and higher risk of presenting a clinical level of Fear of Getting Fat among boys.

Second, results showed a marginally significant association between sex and the status of the participants in the prediction of Social Pressure to Gain Weight, Eating-Related Guilt, and EatingRelated Control. The decomposition of these interactions showed that (a) girls involved in sport practice were more than twice more likely to present clinically significant levels of Eating-Related Control $(O R=2.12 ; 95 \%$ CI: .89-5.07; $p<.10)$ and Social Pressure to Gain Weight $(O R=2.37 ; 95 \%$ CI: .99-5.69; $p=.05$ ) compared with girls not-involved in sport practice; and (b) boys involved in sport practice were 3.4 times less likely to present clinically significant levels of Eating-Related Guilt $(O R=.29 ; 95 \%$ CI: .08-1.05; $p=.06)$ compared with boys not-involved in sport practice. However, no effect of sport-practice status was observed among (a) boys in predicting Eating-Related Control (OR $=.61 ; 95 \%$ CI: .23-1.63; $p=.32)$ and Social Pressure to Gain Weight $(O R=.82 ; 95 \%$ CI: .34-1.96; $p$ $=.66)$, and (b) girls in predicting Eating-Related Guilt (OR = 1.13; 95\% CI: .46-2.77; $p=.79)$. Additional analyses revealed that boys involved in sport practice were 3.2 and 4 times less likely to present clinically significant levels of Eating-Related Control (OR $=.31$; 95\% CI: .09-1.05; $p=.06)$ 
and Eating-Related Guilt (OR = .25; 95\% CI: .06-1.12; $p=.07)$ compared with girls involved in sport practice. Finally, no significant differences were observed between (a) boy and girl involved in sport practice in predicting Social Pressure to Gain Weight (OR =.48; 95\% CI: .15-1.51; $p=.21)$, and (b) boy and girl not-involved in sport practice in predicting Eating-Related Control $(O R=1.09$; 95\% CI: $.67-1.75 ; p=.74)$, Eating-Related Guilt (OR = .97; 95\% CI: .60-1.57; $p=.91)$, and Social Pressure to Gain Weight (OR =1.38; 95\% CI: .88-2.18; $p=.16)$. These results show that sport involvement is associated with higher risk of presenting clinical levels of Eating-Related Control and Social Pressure to Gain Weight for girls, but lower risk of presenting clinical levels of Eating-Related Guilt for boys.

Third, a marginally significant association was found between sex and competition status in the prediction of Vomiting-Purging Behavior, and the decomposition of this interaction revealed that girls involved in competitive sports were 2.6 times more likely to present clinically significant levels of Vomiting-Purging Behavior (OR = 2.56; 95\% CI: 1.01-6.47; $p=.048)$ compared with girls not involved in competitive sports. However, no significant effect of competition status was observed among boys $(O R=.67 ; 95 \% \mathrm{CI}$. .23-1.99; $p=.47)$. Additional analyses revealed that boys involved in competitive sports on were 4.0 times less likely to present a clinically significant levels of VomitingPurging Behavior $(O R=.25$; 95\% CI: .06-1.08; $p=.06)$ compare with girls involved in competitive sports. Nevertheless, no significant differences were observed between boys and girls not involved in competitive sports (OR = .95; 95\% CI: .59-1.53; $p=.83)$. These results show that involvement in competitive sports has apparently particularly deleterious effects amongst girl involved in sport practice, in terms of increasing the risk of indulging in Vomiting-Purging Behaviors.

Age. The results revealed a significant interaction between age and the sport-practice status of the participants in the prediction of Vomiting-Purging Behavior $(p<.05)$. Decomposing this interaction showed that for each increase of one year in age, youths involved in sport practice were 1.6 times less likely to present clinically significant levels of Vomiting-Purging Behavior $(O R=.63$; 95\% CI: .45-.86; $p<.05$ ), an effect that was only marginally significant and substantially reduced among youths not-involved in sport practice $(O R=.91 ; 95 \%$ CI: .82-1.02; $p=.10)$. Thus, the older the youths involved in sport practice are, the lower the risk that they would indulge in Vomiting-Purging Behaviors. 
The interaction between age and involvement in leanness sports also significantly predicted Social Pressure to Gain Weight. More precisely, the decomposition of this interaction showed that for each increase of one year in age, youths not involved in leanness sports were 1.15 times less likely (representing a decrease of 1.75 times over of 5 years period) to present clinically significant levels of Social Pressure to Gain Weight $(O R=.87 ; 95 \%$ CI: .79-.97; $p<.05)$, a relation that fell short of significance in adolescents exercising in leanness sports ( $O R=1.16$; 95\% CI: .88-1.53; $p=.28)$. Thus, involvement in non-leanness sports, over time, is associated with a slight decrease in the risk of presenting clinically levels of Social Pressure to Gain Weight. Inversely, involvement in leanness sports apparently negates this developmental decrease in the risk of presenting clinical levels of Social Pressure to Gain Weight.

One additional interaction was marginally significant and showed an association between age and competition status in the prediction of Fear of Getting Fat. Decomposing this interaction showed that for each increase of one year in age, adolescents not involved in competitive sports where 1.12 times less likely (thus a decrease of thus a decrease of 1.6 times over a five year period) to present clinically significant levels of Fear of Getting Fat (OR = .89; 95\% CI: .79-1.01; $p=.07)$, an effect that was non-significant for adolescents involved in competitive sports $(O R=1.27$; 95\% CI: .84-1.92; $p=$ .25). Thus, involvement in non-competitive sports, over time, is associated with a slight decrease in the risk of presenting clinically levels of Fear of Getting Fat, while this developmental decrease is negated for youths involved in competitive sports.

\section{Discussion}

The present study sought to examine the prevalence and the sport-related predictors of DEAB, and the potential moderating effects of gender and age on these relations using a sample of French adolescent involved or not in regular sport practice. The results from the main, non-moderated logistic regression analyses showed that overall, adolescents involved in sport practice were not at greater risk of DEAB symptoms than adolescents not involved in sport practice. Similarly, none of the sportrelated characteristics considered was found to have a main, non-moderated effect on the risk of presenting clinically significant levels of DEAB. This lack of significant differences is consistent with previous studies (e.g., Hoch et al., 2009; Monthuy-Blanc et al., 2010; Ravaldi et al., 2003; Rosendahl 
et al., 2009) and may be explained by the fact that these studies (as the present one) essentially relied on a population that excludes athletes competing at an elite level, who do not need to rely on extreme weight-control strategies in order to reach extreme levels of performance (see Monthuy-Blanc et al., 2010). Indeed, most of the preceding studies in which effects of sport involvement and characteristics on DEAB were observed relied on samples of elite athletes (e.g., Ferrand et al., 2009; Filaire et al., 2007; Martinsen et al., 2010; Rouveix et al., 2007).

However, the overall pattern of results drastically change when interactions effects involving sex and age are considered and suggest that sport practice and characteristics of the sport context do indeed have an effect on DEAB, but that this effect is modified by the sex and age of the adolescents to such an extent that gender and age difference may explain at least part of the discrepant results observed in previous studies (e.g., Anshel, 2004; Ferrand et al., 2009; Filaire et al., 2007; Hoch et al., 2009; Martinsen et al., 2010; Neümarker et al., 1998; Ravaldi et al., 2003; Rosendahl et al., 2009; Rouveix et al., 2007). Indeed, these results show an association between sport involvement and higher risk of presenting a clinical level of Eating-Related Control and Social Pressure to Gain Weight among girls. These results, especially regarding the effects that are specific to girls, are generally consistent with those reported by previous studies (e.g., Anshel, 2004; Ferrand et al., 2009; Filaire et al., 2007; Neumärker et al., 1998; Rouveix et al., 2007; Van Durme et al., 2012). Due to gender-differentiated mainstream beauty standards and the fact that body weight/shape affect athletic performance levels, girls involved in sport practice may thus be acutely sensitive to body weight/shape dissatisfaction or negative feedback about their body weight/shape, and therefore be more likely to use food control strategies as an effective means to control their body weight/shape (Bonci et al., 2008; Martinsen et al., 2010). Simultaneously, prolonged use of extreme food control strategies may lead to paradoxically opposite pressure from educators, family members, and peers to eat more in order to gain some weight or to develop bigger muscular volume. Since these associations are limited to highly specific facets of DEAB and do not involve the more severe manifestations of DEAB (e.g., Fear of Getting Fat, EatingRelated Guilt, Vomiting-Purging Behavior, etc.), these results are not currently alarming, but suggest that girls involved in sport practice may deserve a more specific type of monitoring than boys for whom the reverse association was found. In particular, girls involved in competitive sports were found 
to present an increased risk of indulging in Vomiting-Purging Behaviors, as if competition reinforced the previously noted tendencies observed in girl involved in sport practice to a level sufficient to push them to more extreme weight control strategies.

Conversely, boy involved in sport practice rather seem to be somehow protected against the development of clinical levels of Food Preoccupation and Eating-Related Guilt. Perhaps due to the mainstream beauty standards among boys who do not value thinness as much as muscularity, which is still an efficient way of performing sports, boys involved in sport practice appear to be less preoccupied by food intake and guilty when they eat, potentially because involvement in sports itself is their way of efficiently managing their weight/shape (Thein-Nissenbaum \& Carr, 2011). In other words, they feel free to eat as much as they want, because they can maintain their body weight/fat at an acceptable level simply by increasing their caloric expenditure through increased period of exercising - simultaneously increasing their athletic performance (Thein-Nissenbaum \& Carr, 2011). This coping method does not seem to be problematic in itself, until as long as adolescents involved in sport practice do not start to simultaneously increasing caloric expenditure while also restricting caloric intake, leading to potentially problematically low energy availability and deleterious health (e.g., growth, maturation, injuries, etc.) and sport-related consequences (Loucks, Kiens, \& Wright, 2011; Sundgot-Borgen \& Garthe, 2011; Thein-Nissenbaum \& Carr, 2011). Such a pattern seems more likely to emerge in leanness sports, where thinness and weight-control becomes an issue even for boys. Indeed, the results also show that involvement in leanness sports was associated with a higher risk of presenting clinical levels of Fear of Getting Fat among boys.

Overall, the results also show that, potentially due to maturational effects, age generally tended to be associated with a lower risk of presenting clinically significant levels of DEAB, particularly in models including the interaction terms. Particularly interesting is the fact that older adolescents involved in sport practice are far less likely than younger ones to rely on the extreme weight control strategy of Vomiting-Purging Behaviors, a tendency that was previously reported in other studies (e.g., Chamay-Weber et al., 2005; Hoek, 2006; Hoek \& van Hoeken, 2003; Smink et al., 2012).

However, it is noteworthy that this otherwise positive developmental trend is moderated by specific characteristics of the sport context. For instance, the results show that involvement in leanness 
sports apparently negates this developmental decrease in the risk of presenting clinical levels of Social Pressure to Gain Weight, potentially because the social network gets used to the specific requirements of the leanness sport context. Similarly, involvement in competitive sports also negates this positive decrease in the risk of presenting clinically levels of Fear of Getting Fat. This interesting effect may be related to the end of pubertal development and maturational growth, when it becomes harder to burn caloric intake on the sole basis of sport practice (for a review see Manini, 2010) while having reached a competitive level of sport practice where it becomes even more important to exert some level of control over one’s body weight/shape.

Conversely, involvement in a sport practiced in an organized or non-organized sport context apparently had no effect on DEAB symptoms, either alone, or in interaction with gender or age. This observation contrasts with the results from one recent study conducted on a sample of female adults (Holm-Denoma et al., 2009). It is probable that the presence of early signs of DEAB may exert an impact on adolescents selection of their sport context based on body-related or self-presentational motives (i.e., monitoring or enhancing their body weight/shape). However, this effect apparently occurs in a non-systematic manner. Indeed, recent studies based on adult samples (Focht \& Hausenblas, 2006; Hausenblas, Brewer, \& Van Raalte, 2004) showed that adults with selfpresentational body weight/shape concerns may choose to exercise in either private (non-organised) or public (organised) exercise environments, but based on the interaction between these specific contexts and their specific profiles of body shape/weight concerns. Consequently, if they feel that their body weight/shape may be negatively assessed by others (thus inducing social physique anxiety) they may prefer to avoid organized sport contexts and prefer to exercise independently (Focht \& Hausenblas, 2006). Conversely, if they have no tendency to experience social physique anxiety but rather like to have external support and felt pressure to get thinner, they may prefer to exercise in an organized context. Clearly, these body-related concerns or self-presentational motives are strongly related to DEAB (Martin-Ginis \& Leary, 2004), making it possible to think that the relationships between the organization of the sport context and DEAB may be moderated by levels of social physique anxiety. Clearly, this hypothesis should be verified in future studies.

Overall, it must still be noted that when all predictors were entered in the equation, the total 
amount of explained variance was low, yet still satisfactory given the gravity and severe consequences associated with clinical levels of DEAB. This observation is however in line with current knowledge on DEAB (e.g., Bonci et al., 2008; Dosil, 2008; Petrie \& Greenleaf, 2007; Thompson \& Sherman, 2010) which are known to emerge from complex biopsychosocial mechanisms involving biological (e.g., hormonal abnormalities, pubertal status, pubertal timing, BMI, etc.), psychological (e.g., physical self-perceptions, social physique anxiety, perfectionism, etc.), and socio-contextual factors (e.g., sport-specific pressures regarding weight, body-shape, and performance, etc.), among which the sport context is just one element. Still, involvement in systematic sport practice may become a major component of one's life and a context where monitoring body/weight shape is part of routine training sessions, providing highly valuable occasion to detect, prevent, and act to modify emerging DEAB tendencies. However, future studies would also do well to investigate the potential effects these additional biopsychosocial factors in the development of DEAB, particularly within the sport context. Four limitations must be taken into account when interpreting these findings. First, in this study less than half of the adolescents exercised in a competitive context and only $7 \%$ of them did so at an elite level. Consequently, it is currently unknown whether the risk of DEAB significantly increase or not with competition level (i.e., no-competition, non-elite level and elite level). This study should thus be replicated relying on a larger sample of adolescents competing at non-elite and elite levels. Second, this study has assessed DEAB by way of self-report questionnaires that may have produced higher than optimal rates of false-positive and false-negative diagnoses due in part to social desirability and attention biases (Jacobi et al., 2004). This limitation may be avoided through the reliance on multiple methods of assessment, such as clinical interview and clinical physical evaluation, and multiple informants. Third, this study mainly relied on attitudes and self-reported behaviors associated with ED, thus neglecting some pathogenic weight control methods (e.g., diuretics, laxatives, diet pills) or symptoms related to the female athletes triad (Thein-Nissenbaum \& Carr, 2011; i.e., energy availability, menstrual function, and bone mineral density) which may both be quite prevalent in the specific profile characterizing athletes suffering from ED. Consequently, the potential associations between these symptoms and sport-related characteristics should be clearly examined in future studies. Fourth, this study relied on a cross-sectional design, precluding investigation of the 
directionality of the associations between DEAB symptoms and the sport-related characteristics. Consequently, it is currently impossible to differentiate whether (a) DEAB adolescents tend to exercising in sport contexts presenting specific characteristics, (b) sport-related characteristics significantly predict the development of DEAB symptoms in otherwise healthy adolescent involved in sport practice; or (c) both, that is DEAB adolescents tend to select specific sports contexts which in turn exacerbate their symptoms. Only longitudinal study will allow these clarifications.

\section{Perspectives}

Current studies on the prevalence and sport-related predictors of DEAB symptoms among adolescent involved in sport practice are limited and generally provide mixed and inconclusive results. These inconsistencies can be attributed to methodological heterogeneity, limitations, and to the fact that these studies have not examined all of the potentially relevant characteristics of the sport context. The present study addressed this limitation and resulted in four main observations. First, adolescents involved in sport practice did not seem to present a greater risk of DEAB than those not-involved in regular sport practice in general, but did present significant relations to DEAD when gender and age differentiated results were considered. Second, sport participation apparently served to protect boys against the development of clinically significant levels of DEAB, whereas it seemed to increase the risk of developing clinically significant levels of DEAB among girls. Third, the risk of presenting clinically significant levels DEAB seems to decrease with age in adolescents involved in sport practice as well as for not involved in regular sport practice. However, this beneficent developmental trend seemed to be negated for adolescents involved in leanness, and competitive sports. Fourth, the practice of competitive sports seemed to increase the risk of using problematic Vomiting-Purging weightcontrol strategies among girls. However, involvement in leanness sports was also associated with a higher risk of presenting clinical levels of Fear of Getting Fat among boys. This study this suggest the importance of implementing monitoring, preventive and early intervention mechanisms within the sport context, particularly for adolescent girls.

\section{Endnotes}

\footnotetext{
${ }^{1}$ Studies examining differences between self-reported and objective measures of anthropometric characteristics (i.e., height and weight) have indicated that self-report measures may be biased to
} 
some extent in adolescents (e.g., Brettschneider et al., 2011; Davis \& Gergen, 1994; De Vriendt, Huybrechts, Ottevaere, Van Trimpont, \& De Henauw, 2009; Fonseca et al., 2010; Goodman, Hinden, \& Khandelwal, 2000). This bias may lead to a slight underestimation of prevalence rates of overweight and obesity, and an overestimation of prevalence rates for underweight. Nevertheless, these studies showed that this bias in prevalence rates was either trivial or non-significant (e.g., Brettschneider et al., 2011; Davis \& Gergen, 1994; De Vriendt et al., 2009; Fonseca et al., 2010; Goodman et al, 2000). Consequently, the general conclusions from these studies are that self-reported BMI may be confidently used for BMI estimates, especially in the context of large scale epidemiological studies.

${ }^{2}$ The score of the vomiting-purging behavior scale for the boys was based on the $90^{\text {th }}$ percentile given that the same score (i.e., 2) was obtained by participants from the $5^{\text {th }}$ to the $85^{\text {th }}$ percentile.

\section{Acknowledgement}

The authors wish to thank all the adolescents, schools, school directors, teachers that participated to this study and the research assistant that was involved in this study.

\section{References}

Abraham S. Characteristics of eating disorders among young ballet dancers. Psychopathology 1996: 29: $218-222$.

Anshel MH. Sources of disordered eating patterns between ballet dancers and non-dancers. J Sport Behav 2004: 27: 115-133.

Baum A. Eating disorders in the male athlete. Sports Med 2006: 36: 1-6.

Beals K. Disordered eating among athletes. A comprehensive guide for health professionals. Champaign: Human Kinetics, 2004.

Beals K, Manore M. The prevalence and consequences of subclinical eating disorders in female athletes. Int J Sport Nutr 1994: 4: 175-195.

Bonci CM, Bonci LJ, Granger LR, Johnson CL, Malina RM, Milne LW, Ryan RR, Vandebunt EM. National athletic trainers' association position statement: Preventing, detecting, and managing disordered eating in athletes. J Athl Train 2008: 43: 80-108.

Brettschneider A-K, Rosario AS, Ellertand U. Validity and predictors of BMI derived from self- 
reported height and weight among 11- to 17-year-old German adolescents from the KiGGS study. BMC Res Notes 2011: 4: 414.

Byrne S, McLean N. Eating disorders in athletes: A review of the literature. J Sci Med Sport 2001: 4: 145-159.

Chamay-Weber C, Narring F, Michaud P-A. Partial eating disorders among adolescents: A review. J Adolesc Health 2005: 37: 417-427.

Coelhlo GMO, Soares EA, Ribeiro BG. Are female athletes at increased risk for disordered eating and its complications? Appetite 2010: 55: 379-387.

Cole TJ. A method for assessing age-standardized weight-for-height in children seen cross-sectionally. Ann Hum Biol 1979: 6: 249-268.

Cole TJ, Bellizzi MC, Flegal KM, Dietz WH. Establishing a standard definition for child overweight and obesity: International survey. BMJ 2000: 320: 1240-1243.

Cole TJ, Flegal KM, Nicholls D, Jackson AA. Body mass index cut offs to define thinness in children and adolescents: International survey. BMJ 2007: 335: 1194-1197.

Davis H, Gergen PJ. The weights and heights of Mexican-American adolescents: the accuracy of selfreports. Am J Public Health 1994: 84: 459-62.

De Vriendt T, Huybrechts I, Ottevaere C, Van Trimpont I, De Henauw S. Validity of self-reported weight and height of adolescents, its impact on classification into BMI-categories and the association with weighing behaviour. Int J Environ Res Public Health 2009: 6: 2696-2711.

Dosil, J. Eating disorders in athletes. Chichester: Wiley \& Sons Ltd, 2008.

Ferrand C, Champely S, Filaire E. The role of body-esteem in predicting disordered eating symptoms: A comparison of French aesthetic athletes and non-athletic females. Psychol Sport Exerc 2009: 10: 373-380.

Filaire E, Rouveix M, Bouget M, Pannafieux C. Prévalence des troubles du comportement alimentaire chez le sportif. Sci Sports 2007: 22: 135-142.

Focht BC, Hausenblas HA. Exercising in public and private environments: Effects on feeling states in women with social physique anxiety. J Appl Biobehav Res 2006: 11: 147-165.

Fonseca, H, Silva AM, Matos MG, Esteves I, Costa P, Guerra A, Gomes-Pedro J. Validity of BMI 
based on self-reported weight and height in adolescents. Acta Pædiatr 2010: 99: 83-88;

Garner DM, Olmstead MP, Bohr Y, Garfinkel PE. The Eating Attitude Test: Psychometric features and clinical correlates. Psychol Med 1982: 12: 871-878.

Glazer JL. Eating disorders among male athletes. Curr Sports Med Rep 2008, 7, 332-337.

Goodman E, Hinden B, Khandelwal S. Accuracy of teen and parental reports of obesity and body mass index. Pediatrics 2000: 106: 52-8.

Hausenblas HA, Brewer BW, Van Raalte JL. Self-presentation and exercise. J Appl Sport Psychol 2004: 16: 3-18.

Hausenblas HA, Carron A. Eating disorders indices and athletes: An integration. J Sport Exerc Psychol 1999: 21, 230-258.

Hoch AZ, Pajewski NM, Moraski LA, Carrera GF, Wilson CR, Hoffmann RG, Schimke JE, AAS, Gutterman DD. Prevalence of the female athlete triad in high school athletes and sedentary students. Clin J Sport Med 2009: 19: 421-428.

Hoek HW. Incidence, prevalence and mortality of anorexia nervosa and other eating disorders. Curr Opin in Psychiatr 2006: 19: 389-394.

Hoek HW, van Hoeken D. Review of the prevalence and incidence of eating disorders. Int J Eating Disord 2003: 34: 383-396.

Holm-Denoma JM, Scaringi V, Gordon KH, Van Orden KA, Joiner TE. Eating disorder symptoms among undergraduate varsity athletes club athletes independent exercisers and nonexercisers. Int J Eat Disord 2009: 42: 47-53.

Jacobi C., Abascal L., Taylor CB. Screening for eating disorders and high-risk behavior: Caution. Int J Eating Disord 2004: 36: 280-295.

Krentz EM, Warschburger P. A longitudinal investigation of sports-related risk factors for disordered eating in aesthetic sports. Scand J Med Sci Sports 2011. Advance online publication. doi: $10.1111 / \mathrm{j} .1600-0838.2011 .01380 . x$

Louks AB, Kiens B, Wright HH. Energy availability in athletes. J Sports Sci 2011: 29(S1): S7-S15.

Manini TD. Energy expenditure and aging. Ageing Res Rev 2010: 9: 1-11.

Madison JK, Ruma SL. Exercise and athletic involvement as moderators of severity in adolescents 
with eating disorders. J Appl Sport Psychol 2003: 15: 213-222.

Maïano C, Morin AJS, Lanfranchi M-C, Therme P. The Eating Attitudes Test-26 Revisited using Exploratory Structural Equation Modeling (ESEM). Manuscript submitted for publication, 2012.

Martin-Ginis KA, Leary MR. Self-presentational processes in health-damaging behavior. J Appl Sport Psychol 2004; 16: 59-74.

Martinsen M, Bratland-Sanda S, Eriksson AK, Sundgot-Borden J. Dieting to win or to be thin? A study of dieting and disordered eating among adolescent elite athletes and non-athlete controls. Br J Sports Med 2010: 44: 70-76.

Monthuy-Blanc J, Maïano C, Therme P. Prevalence of eating disorders symptoms in non-elite ballet dancers and basketball players: An exploratory and controlled study among French adolescent girls. Rev Epidemiol Sante Publique 2010: 58: 415-424.

Mota J, Esculcas C. Leisure-time physical activity behavior: Structured and unstructured choices according to sex, age, and level of physical activity. Int J Behav Med 2002: 9: 111-121.

Neumärker KJ, Bettle N, Bettle O, Dudeck U, Neumärker U. The eating attitude test: Comparative analysis of female and male students at the public ballet school of Berlin. Eur Child Adolesc Psychiatry 1998: 7: 19-23.

Nichols JF, Rauh MJ, Barrack MT, Barkai HS, Pernick Y. Disordered eating and menstrual irregularity in high school athletes in lean-build and nonlean-build sports. Int J Sport Nutr Exerc Metab 2007: 17: 364-377.

Nichols JF, Rauh MJ, Lawson MJ, Ji M, Barkai HS. Prevalence of the female athlete triad syndrome among high school athletes. Arch Pediatr Adolesc Med 2006: 160: 137-142.

Petrie TA, Greenleaf CA. Eating disorders in sport: from theory to research to intervention. In: Tenenbaum G, Eklund RC, editors. Handbook of sport psychology, 3rd ed. Hoboken, NJ: Wiley: 2007. pp. 352-378.

Rauh MJ, Nichols JF, Barrack MT. Relationship between injury and disordered eating, menstrual irregularity, and low BMD among high school athletes. J Athl Train 2010: 45: 243-252

Ravaldi C, Vannacci A, Zucchi T, Mannucci E, Cabras PL, Boldrini M, Murciano L, Rotella CM, 
Ricca V. Eating disorders and body image disturbances among ballet dancers, gymnasium users and body builders. Psychopathology 2003: 36: 247-254.

Rosendahl J, Bormann B, Aschenbrenner K, Strauss B. Dieting and disordered eating in German high school athletes and non-athletes. Scand J Med Sci Sports 2008: 19: 731-739.

Rouveix M, Bouget M, Pannafieux C, Champely S, Filaire E. Eating attitudes body esteem perfectionism and anxiety of judo athletes and non-athletes. Int J Sports Med 2007: 28: 340345.

Santos MP, Gomes H, Mota J. Physical activity and sedentary behaviors in adolescents. Ann Behav Med 2005: 30: 21-24.

Smink FRE, van Hoeken D, Hoek HW. Epidemiology of eating disorders: Incidence, prevalence and mortality rates. Curr Psychiatr Rep 2012. Advance online publication. doi: 10.1007/s11920012-0282-y

Smolak L, Murnen S, Ruble A. Female athletes and eating problems: A meta-analysis. Int J Eat Disord 2000: 27: 371-380.

Sundgot-Borgen J. Eating disorders in female athletes. Sports Med 1994: 17: 176-188.

Sundgot-Borgen J, Garthe I. Elite athletes in aesthetic and Olympic weight-class sports and the challenge of body weight and body compositions. J Sports Sci 2011: 29(S1): S101-S114.

Tamminen KA, Holt NL, Crocker PRE. Adolescent athletes: Psychosocial challenges and clinical concerns. Curr Opin Psychiatr 2012: 25: 293-300.

Thein-Nissenbaum JM, Carr KE. Female athlete triad syndrome in the high school athlete. Phys Ther Sport 2011: 12: 108-116.

Thein-Nissenbaum JM, Rauh MJ, Carr KE, Loud KJ, McGuine, TA. Associations between disordered eating, menstrual dysfunction, and musculoskeletal injury among high school athletes. J Orthop Sports Phys Ther 2011: 41: 60-69.

Thompson RA, Sherman RT. Athletes, athletic performance, and eating disorders : Healthier alternatives. J Soc Issues 1999: 55: 317-337.

Thompson RA, Sherman RT. Eating disorders in sport. New York: Routledge, 2010.

Toro J, Galilea B, Martinez-Mallén E, Salamero M, Capdevila L, Marı J, Mayolas J, Toro E. Eating 
disorders in Spanish female athletes. Int J Sports Med 2005: 26: 693-700.

Toro J, Guerrero M, Sentis J, Castro J, Puértolas C. Eating disorders in ballet dancing students: Problems and risk factors. Eur Eat Disord Rev 2009: 17: 40-49.

Van Durme K, Goossens L, Braet C. Adolescent aesthetic athletes: A group at risk for eating pathology? Eat Behav 2012: 13: 119-122. 
Table 1.

Descriptive Statistics for Demographic, Anthropometric, Ethnicity and Weight Categories According to Sport Involvement and Sex

\begin{tabular}{|c|c|c|c|c|c|c|c|c|c|c|}
\hline \multirow{3}{*}{$\begin{array}{l}\text { Variables } \\
\text { Demographic/anthropometric }\end{array}$} & \multicolumn{2}{|c|}{ Total } & \multicolumn{2}{|c|}{ Boys } & \multicolumn{2}{|c|}{ Girls } & \multirow{2}{*}{\multicolumn{2}{|c|}{ Status }} & \multirow{2}{*}{\multicolumn{2}{|c|}{ Sex }} \\
\hline & \multirow{2}{*}{$\begin{array}{c}\text { Involved } \\
(n=335)\end{array}$} & \multirow{2}{*}{$\begin{array}{l}\text { Not- Involved } \\
(n=435) \\
M(S D)\end{array}$} & \multirow{2}{*}{$\begin{array}{c}\text { Involved } \\
(n=168)\end{array}$} & \multirow{2}{*}{$\begin{array}{l}\text { Not- Involved } \\
\qquad \frac{(n=173)}{M(S D)}\end{array}$} & \multirow{2}{*}{$\begin{array}{c}\text { Involved } \\
(n=167)\end{array}$} & \multirow{2}{*}{$\begin{array}{l}\text { Not- Involved } \\
(n=262) \\
M(S D)\end{array}$} & & & & \\
\hline & & & & & & & $Z$ & $p$ & $Z$ & $p$ \\
\hline Age [years] & $14.50(2.07)$ & $14.69(2.16)$ & 14.37 (1.98) & $14.49(2.10)$ & $14.63(2.15)$ & $14.82(2.19)$ & -1.23 & .22 & -2.06 & .04 \\
\hline Weight [kg] & $55.88(14.58)$ & $53.93(11.34)$ & $58.35(17.61)$ & $56.16(13.20)$ & $53.40(10.15)$ & 52.45 (9.68) & -1.87 & .06 & -4.19 & $<.001$ \\
\hline Height [Meters] & $1.65(.11)$ & $1.65(.11)$ & $1.69(.13)$ & 1.68 (.13) & $1.62(0.8)$ & $1.63(.08)$ & -0.81 & .42 & -8.32 & $<.001$ \\
\hline BMI $\left[\mathrm{kg} / \mathrm{m}^{2}\right]$ & 20.17 (3.37) & $19.75(3.03)$ & 20.17 (3.73) & $19.74(2.87)$ & $20.18(2.98)$ & $19.76(3.13)$ & -1.75 & .08 & -0.17 & .87 \\
\hline Ethnicity & $\%(n)$ & $\%(n)$ & $\%(n)$ & $\%(n)$ & $\%(n)$ & $\%(n)$ & $\chi^{2}(2)$ & $p$ & $\chi^{2}(2)$ & $p$ \\
\hline European & 70.7 (237) & $66.7(290)$ & $70.2(118)$ & $74.0(128)$ & 71.3 (119) & $61.8(162)$ & & & & \\
\hline African & $23.3(78)$ & $27.8(121)$ & $28(47)$ & $22.0(38)$ & $18.6(31)$ & $31.7(83)$ & 2.033 & .36 & 9.71 & .008 \\
\hline Others & $6.0(20)$ & $5.5(24)$ & $1.8(3)$ & $4.0(7)$ & $10.2(17)$ & $6.5(17)$ & & & & \\
\hline Weight categories & $\%(n)$ & $\%(n)$ & $\%(n)$ & $\%(n)$ & $\%(n)$ & $\%(n)$ & $\chi^{2}(2)$ & $p$ & $\chi^{2}(2)$ & $p$ \\
\hline Underweight & $8.1(27)$ & $12.4(54)$ & $7.7(13)$ & $7.5(13)$ & $8.4(14)$ & $15.6(41)$ & & & & \\
\hline Normal weight & $78.8(264)$ & 77.9 (339) & $73.8(124)$ & $80.9(140)$ & $83.8(140)$ & 76 (199) & 5.48 & .07 & 12.80 & .002 \\
\hline Overweight-obese & $13.1(44)$ & $9.7(42)$ & $18.5(31)$ & $11.6(20)$ & 7.8 (13) & $8.4(22)$ & & & & \\
\hline
\end{tabular}

Note. $\mathrm{BMI}=$ body-mass index; $S D$ = standard deviation. 
Table 2.

Hierarchical Multivariate Logistic Regression Models Predicting Disturbed Eating Attitudes and Behavior Scales

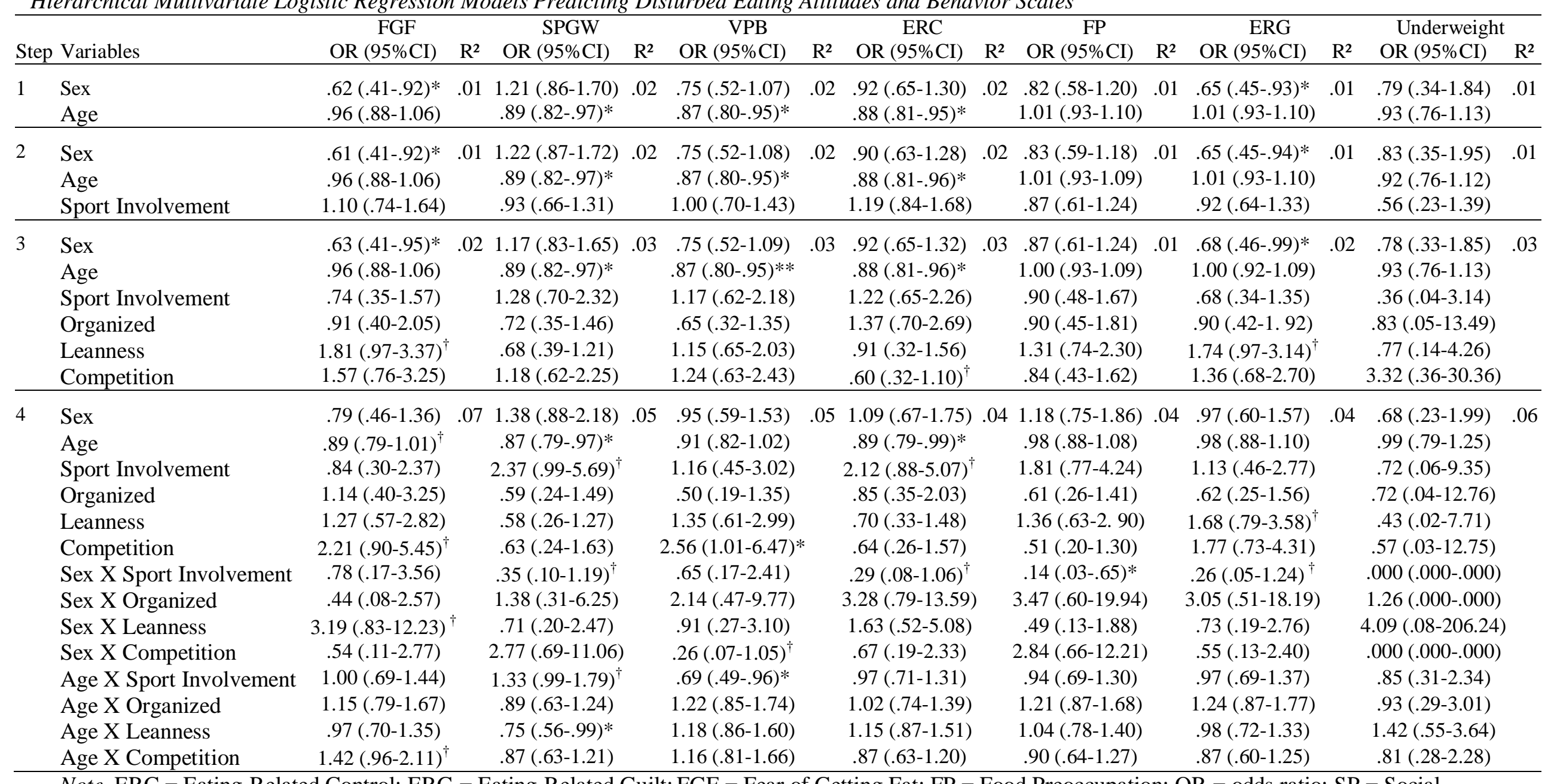

Note. ERC = Eating-Related Control; ERG = Eating-Related Guilt; FGF = Fear of Getting Fat; FP = Food Preoccupation; OR = odds ratio; SP = Social

Pressure to Gain Weight; VPB = Vomiting-Purging Behavior; 95\%CI = odds ratio 95\% confidence interval. ${ }^{*} p<.05 .{ }^{\dagger} p<.10$. 


\section{Supplemental Materials for:}

Prevalence and Sport-Related Predictors of Disturbed Eating Attitudes and Behaviors:

Moderating Effects of Sex and Age

Table S1.

Classification of the 46 Different Sports

\begin{tabular}{cc}
\hline Leanness & Non-Leanness \\
\hline Dancing $(n=37)$ & Alpine skiing $(n=1)$ \\
HipHop $(n=6)$ & Badminton $(\mathrm{n}=5)$ \\
Figure skating $(n=1)$ & Tennis $(n=26)$ \\
Gymnastics $(n=3)$ & Water polo $(n=1)$ \\
Combat: Boxing $(n=3)$, Kickboxing $(n=2)$, & American football $(\mathrm{n}=1)$ \\
French savate $(n=1)$, Wrestling $(n=2)$ & Rugby $(n=5)$ \\
Martial Arts: Aïkido $(n=1)$, Judo $(n=9)$, Karate & Basketball $(n=24)$, \\
$(n=5)$, Kung Fu $(n=1)$, Taekwondo $(n=3)$ & Soccer $(\mathrm{n}=76)$ \\
Fitness $(n=7)$ & Handball $(n=14)$ \\
Rowing $(n=1)$ & Volleyball $(n=11)$ \\
Swimming $(n=17)$ & Shooting $(n=1)$ \\
Cycling $(n=8)$ & Archery $(n=2)$ \\
Jogging $(n=14)$ & Pétanque $($ Bowls $(n=1)$ \\
Mountain-biking $(n=2)$ & Fishing $(n=1)$ \\
Rock climbing $(n=9)$ & Golf $(n=1)$ \\
Twirling $(n=1)$ & Rollerblading $(n=1)$ \\
Olympic walk $(n=1)$ & Horse riding $(n=9)$ \\
& Pelota $(n=1)$ \\
& Power lifting $(n=6)$ \\
& Sailing $(n=2)$ \\
& Scuba diving $(n=1)$ \\
& Skateboard $(n=1)$ \\
& Table tennis $(n=9)$ \\
&
\end{tabular}


Table S2.

Prevalence Rates of Disturbed Eating Attitudes and Behaviors According to Demographics and Sport-Related Characteristics

\begin{tabular}{|c|c|c|c|c|c|c|c|c|c|c|c|c|c|}
\hline \multirow[b]{2}{*}{ Variables } & \multicolumn{2}{|c|}{ Fear of Getting Fat } & \multicolumn{2}{|c|}{$\begin{array}{l}\text { Social Pressure to } \\
\text { Gain Weight }\end{array}$} & \multicolumn{2}{|c|}{$\begin{array}{c}\text { Vomiting-Purging } \\
\text { Behavior }\end{array}$} & \multicolumn{2}{|c|}{$\begin{array}{c}\text { Eating-Related } \\
\text { Control }\end{array}$} & \multicolumn{2}{|c|}{ Food Preoccupation } & \multicolumn{2}{|c|}{ Eating-Related Guilt } & Underweight \\
\hline & $\begin{array}{c}\text { Non at-risk } \\
n(\%)\end{array}$ & $\begin{array}{l}\text { At-risk } \\
n(\%)\end{array}$ & $\begin{array}{c}\text { Non at-risk } \\
n(\%)\end{array}$ & $\begin{array}{c}\text { At-risk } \\
n(\%)\end{array}$ & $\begin{array}{c}\begin{array}{c}\text { Non at-risk } \\
n(\%)\end{array} \\
\end{array}$ & $\begin{array}{c}\text { At-risk } \\
n(\%)\end{array}$ & $\begin{array}{c}\text { Non at-risk } \\
n(\%)\end{array}$ & $\begin{array}{c}\text { At-risk } \\
n(\%)\end{array}$ & $\begin{array}{c}\text { Non at-risk } \\
n(\%)\end{array}$ & $\begin{array}{c}\text { At-risk } \\
n(\%)\end{array}$ & $\begin{array}{c}\text { Non at-risk } \\
n(\%)\end{array}$ & $\begin{array}{c}\text { At-risk } \\
n(\%)\end{array}$ & $\begin{array}{cc}\text { Non at-risk } & \text { At-risk } \\
n(\%) & n(\%)\end{array}$ \\
\hline
\end{tabular}

Sex

Girls $350(81.6) 79(18.4) \quad 338(78.8) 91(21.2) \quad 334(77.9) \quad 95(22.1) \quad 335$ (78.1) $94(21.9) 329(76.7) 100(23.3) \quad 332(77.4) 97(22.6) 415(96.7) 14(3.3)$

Boys $299(87.7) 42(12.3) \quad 255(74.8) \quad 86(25.2) \quad 279(81.8) \quad 62(18.2) \quad 269(78.9) \quad 72(21.1) 273(80.1) \quad 68(19.9) \quad 287(84.2) 54(15.8) \quad 332(97.4) \quad 9(2.6)$

Sport-Involvement

Not-involved $368(84.6) 67(15.4) \quad 334(76.8) 101(23.2) \quad 346(79.5) \quad 89(20.5) \quad 347(79.8) 28(20.2) \quad 335(77) \quad 100(23) \quad 346(79.5) 89(20.5) 419(96.3) \quad 16(3.7)$ Involved $281(83.9) \quad 54(16.1) \quad 259(77.3) \quad 76(22.7) \quad 267(79.7) \quad 68(20.3) \quad 257(76.7) 78(23.3) 267(79.7) \quad 68(20.3) \quad 273(81.5) 62(18.5) \quad 328(97.9) \quad 7(2.1)$

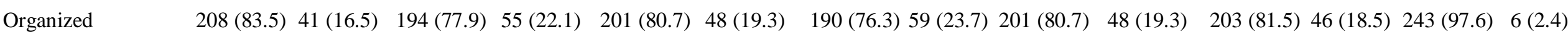

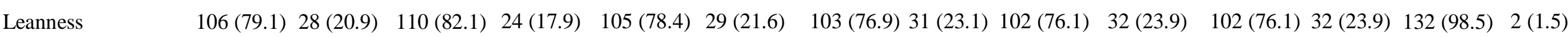



